\title{
SIGURNOST I ETNIČKI ODNOSI - PERCEPCIJA PROBLEMA U KONTEKSTU NASELJA I SUŽIVOTA
}

\author{
Božidar Filipović ${ }^{1}$ \\ $\mathrm{UDK}=316.47: 364.652(497.11)$ \\ https://doi.org/10.18485/fb_ubur.2018.1.ch4 \\ ${ }^{1}$ Univerzitet u Beogradu - Filozofski fakultet, Odeljenje za sociologiju, \\ filipovic.bozidar1@gmail.com
}

\section{Sažetak}

U radu će biti prezentovani rezultati kvalitativnog istraživanja koje je sprovedeno na teritoriji Grada Beograda. Usredsređujući se na metodološko pitanje validnosti, pristupili smo rezultatima kvantitativnog sociološkog istraživanja društvene strukture, kakva se od osamdesetih godina XX veka sprovode u Srbiji, odnosno bivšoj Jugoslaviji, pod rukovodstvom prof. dr Mladena Lazića. Jedan od iskaza korišćenih u navedenom istraživanju odnosi se upravo na pitanje sigurnosti, a glasi: „Čovek se može osećati sasvim sigurnim samo kada živi u sredini gde je većina pripadnika njegove nacije." $\mathrm{S}$ obzirom na to da su u navedenim kvantitativnim istraživanjima odgovori uvek bili unapred definisani, odnosno ograničeni okvirima Likertove skale, želeli smo da odgovore na ovo (isto) pitanje kritički promislimo. Stoga smo u jednom delu svog (kvalitativnog) istraživanju osmislili niz potpitanja koja su nam dodatno razjasnila odgovore ispitanikâ i pokazala na koji način shvataju ključne elemente navedenog iskaza. Dakle, prezentovaćemo interpretaciju problemâ i izazovâ sigurnosti u kontekstu međuetničkih odnosa. Preciznije, pokušaćemo da razumemo zašto se ispitanici određuju prema iskazu na vrednosno pozitivan ili negativan način te kako sami objašnjavaju svoja opredeljenja.

Ključne reči: sigurnost, etnički odnosi, kvalitativna i kvantitativna metodologija, interpretacija

\section{Uvod}

Rasprave i sporenja o upotrebi različitih metoda u istraživanju društvenih fenomena ispoljavaju se od samih početaka sociologije kao nauke. Rascep ili vododelnica koja razgraničava zastupnike suprotstavljenih 'tabora' najčešće se proteže po liniji koja razdvaja kvantitativne od kvalitativnih metoda. ${ }^{1}$ Iako se u udžbenicima i priručnicima kao željeni ideal često postulira metodološka triangulacija,

1 Neki autori su skloni da distinkciju vide kao razliku između dve kulture (Goertz, C. \& Mahoney, J.: A Tale of Two Cultures: Qualitative and Quantitative Research in the Social Sciences, Princeton university press, 2012, Princeton, pp. vii). 
istraživanja se, nažalost, često ograničavaju na samo jedan od mogućih pristupa. Razlog za korišćenje više različitih metoda pronalazi se u kompatibilnosti kvalitativnog i kvantitativnog pristupa. ${ }^{1}$ Svaki metodološki pristup ima svoje, manje ili više poznate, prednosti i nedostatke, te se kroz triangulaciju ostvaruje potpuniji pristup u istraživanju željenih pojava.

Međutim, u središtu naše pažnje neće biti pitanje triangulacije u istraživanjima etničkih odnosa ili bezbednosnih problema. Želimo da se u radu posvetimo problemu metodološke valjanosti (validnosti) kvantitativnih empirijskih istraživanja. Istraživanju problema metodološke valjanosti pristupili smo empirijski, a kao početnu 'tačku' našeg istraživanja odabrali smo kvantitativne podatke. Od 1989. godine u Jugoslaviji, odnosno Srbiji, sproveden je niz istraživanja društvene strukture pod rukovodstvom prof. dr Mladena Lazića: ${ }^{2}$

1989 - Društvena struktura i kvalitet života. Istraživanje je sprovedeno na području SFRJ, 1989. godine, na uzorku od 13.422 ispitanika/-ca, u organizaciji Konzorcija socioloških i srodnih instituta Jugoslavije.

2003 - Stratifikacijske $i$ vrednosne promene u periodu društvene transformacije. Sprovedeno je na uzorku od 2.997 ispitanika/-ca, u okviru projekta SEESSP (South East European Social Survey Project) na teritoriji šest zemalja jugoistočne Evrope u periodu 2003-2004.

2012 - Promene osnovnih struktura srpskog društva realizovano je na teritoriji cele Srbije u prvoj polovini 2012. godine u organizaciji ISI FF. Podaci su prikupljeni na reprezentativnom uzorku od 2.500 ispitanika/-ca.

Navedena istraživanja smo odabrali kao polaznu tačku jer u domaćoj sociologiji imaju najduži kontinuitet i svakako predstavljaju najznačajnija istraživanja društvene strukture u Srbiji. U istraživanjima je deo upitnika uvek bio posvećen vrednosnim orijentacijama ispitanika/-ca. Orijentacije su istraživane na osnovu niza iskaza, odnosno pitanja na koja su ispitanici/-ce davali unapred ponuđene odgovore formirane pomoću tzv. Likertove skale. ${ }^{3}$ Cilj ovog rada jeste pokušaj utvrđivanja značenja koja ispitanici/ce pridaju datim ('zaokruženim') odgovorima na Likertovoj skali. Drugim rečima, otišli smo korak dalje od navedenih kvantitativnih istraživanja.

Uz pomoć kvalitativne metodologije pokušali smo da dobijemo odgovor na naizgled jednostavna pitanja - kakve su interpretacije pitanja (iskaza) od strane subjekata i kakva značenja pridaju sopstvenim odgovorima? Odmah moramo napomenuti da u obzir nismo uzeli sva pitanja koja se u navedenim kvantitativnim

1 Naravno, saznajno plodonosno može biti i kombinovanje metoda koje se nalaze na samo jednoj strani ove 'velike' podele.

2 Neka od pitanja koja su relevantna za naš rad, a korišćena su o navedenim istraživanjima, javljala su se i u drugim istraživanjima, te ih ne možemo na ovome mestu pobrojati u celosti.

3 Videti više: Lazić, M.: Čekajući kapitalizam: nastanak novih klasnih odnosa u Srbiji, Službeni glasnik, 2011, Beograd; Lazić, M. (prir.): Politička elita u Srbiji u periodu konsolidacije kapitalističkog poretka, Čigoja, ISI, Beograd, 2016; Petrović, I.: „Promene vrednosnih orijentacija srednje klase u periodu post-socijalističke transformacije u Srbiji“, Sociologija, Vol. LV (2013), N 3, str. $375-394$. 
istraživanjima javljaju u vezi sa vrednosnim orijentacijama učesnikâ. Još važnije, u ovom radu ćemo pažnju posvetiti analizi samo jednog pitanja: „Čovek se može osećati sasvim sigurnim samo kada živi u sredini gde je većina pripadnika njegove nacije."

No, vrátimo se problemu metodološke validnosti. Šta podrazumevamo pod ovim pojmom? Stanislav Fajgelj smatra da se tzv. konstruktivna valjanost javlja kao sinonim za valjanost uopšte: „U ovom tipu valjanosti se daje odgovor na pitanje šta meri merni instrument, pa se danas ovo pitanje najčešće sreće kao definicija validnosti uopšte. “1 Navedenu definiciju smatramo zadovoljavajućom za početnu tačku našeg kvalitativnog istraživanja. Ipak, prihvatamo je uz važnu napomenu. Naše kvalitativno istraživanje validnosti ne započinjemo od samog početka - definicije pojma na koje se navedeni iskaz ${ }^{2}$ odnosi - kako bismo putem niza novih metodoloških 'međukoraka' dospeli do iskustvenih podataka neophodnih za potvrđivanje ili opovrgavanje metodološke valjanosti indikatora korišćenih u navedenim kvantitativnim istraživanjima.

Sa druge strane, iz istih razloga, naše istraživanje nije ni pokušaj naknadnog ostvarivanja metodološke triangulacije kako bismo dospeli do konačnog (ili ma kakvog) suda o validnosti navedenih indikatora u kvantitativnim istraživanjima. Razlog se opet krije u pristupu koji nastavlja od 'tačke' na kojoj kvantitativna istraživanja završavaju - samih indikatora kao polazište osnove za razgovor. Stoga se u našem slučaju ne bi mogla primeniti Džikova (Jick) definicija triangulacije. ${ }^{3}$

No, šta se zapravo u navedenim kvantitativnim istraživanjima merilo pomoću navedenog indikatora, odnosno gore navedene rečenice? $?^{4}$ Iskazom je merena nacionalistička orijentacija ispitanika/-ca. Slaganje sa iskazom je značilo i viši stepen nacionalističke orijentacije, ili, još preciznije, veći stepen nacionalističkog ekskluzivizma, ${ }^{5}$ koji je definisan na sledeći način:

„Nacionalistički ekskluzivizam, kojim se definiše stepen vezanosti za sopstvenu nacionalnu (etničku) grupu, ali i odnos prema drugim etničkim ili nacionalnim grupacijama, koji je, po pravilu, određen konkretnim društveno-istorijskim

1 Fajgelj, S.: Metode istraživanja ponašanja, Centar za primenjenu psihologiju, 2010, Beograd, str. 462.

2 Gore navedeni iskaz.

3 'This kind of triangulation is labeled by Denzin (1978: 302) as the 'between (or across) methods' type, and represents the most popular use of triangulation It is largely a vehicle for cross validation when two or more distinct methods are found to be congruent and yield comparable data. For organizational researchers, this would involve the use of multiple methods to examine the same dimension of a research problem. For example, the effectiveness of a leader may be studied by interviewing the leader, observing his or her behavior, and evaluating performance records. The focus always remains that of the leader's effectiveness but the mode of data collection varies. Multiple and independent measures, if they reach the same conclusions, provide a more certain portrayal of the leadership phenomenon." (Jick, T.: "Mixing Qualitative and Quantitative Methods: Triangulation in Action", Administrative Science Quarterly, Vol. 24, No. 4, pp. 602-611.)

4 Ona je bila samo jedan od indikatora unutar dimenzije nacionalističkog ekskluzivizma.

5 U pitanju je dimenzija 'unutar' pojma nacionalističke orijentacije. 
kontekstom. Ova dimenzija se delimično poklapa sa etnocentrizmom (s tim da je ovaj drugi pojam znatno širi, jer obuhvata i prosuđivanje pripadnika drugih nacija na osnovu vrednosnih atributa sopstvene grupe).“1

\section{Kvalitativno istraživanje}

Istraživanje je sprovedeno na kvotnom uzorku od 20 učesnika/-ca u periodu od septembra 2016. do juna 2017. godine na području grada Beograda. Uzorak je sačinjavalo po deset ispitanika i ispitanica i okviru sledeće starosne strukture: od 18 do 30 godina (4 subjekta), od 31 do 45 godina ( 7 ispitanika/-ca), od 46 do 60 godina (5 osoba) i više od 61 godine starosti (4 ispitanika/-ce). U pogledu obrazovne strukture uzorak sačinjava jedna ispitanica sa završenom osnovnom školom, 16 ispitani$\mathrm{ka} /$-ca sa završenom srednjom školom, dve ispitanice sa nezavršenim fakultetom $\mathrm{i}$ jedan ispitanik sa završenim fakultetom. ${ }^{2}$

Kvalitativno istraživanje je sprovedeno na osnovu polustrukturisanog intervjua. Osnova za razgovor (osim 'uvodnih' pitanja koja su se odnosila na sociodemografske karakteristike subjekata) bila je sačinjena od 25 pitanja/iskaza preuzetih iz pomenutih kvantitativnih istraživanja. ${ }^{3}$ Na navedena pitanja subjekti su davali odgovore koji su formirani na osnovu Likertove skale. Ponuđeni odgovori u bili: 1 - „, u potpunosti se slažem“, 2 - „slažem se“, 3 - „niti se slažem, niti se ne slažem“, 4 - ,,ne slažem se“, 5 - ,u potpunosti se ne slažem“ i 8 - „, ne znam“. Pošto su ispitanici/-ce dali jedan od ponuđenih odgovora, postavljeno im je (pot)pitanje: „Kako ste Vi razumeli ovaj iskaz?“ U zavisnosti od njihovog odgovora ${ }^{4}$ postavljana su i ostala potpitanja.

Ponovimo, u radu ćemo se ograničiti na samo jedno pitanje i odgovore učesnika/-ca koje smo dobili u našem kvalitativnom istraživanju: „Čovek se može osećati sasvim sigurnim samo kada živi u sredini gde je većina pripadnika njegove nacije.“ Odgovore koji slede dobili smo nakon (pot)pitanja: „Kako ste shvatili iskaz?“"

1 Pešić, J.: Vrednosne orijentacije u post-socijalističkim društvima Srbije i Hrvatske [doktorska disertacija], 2016, Beograd, str. 494-495.

2 Sve razgovore je lično vodio autor ovog rada i nakon svakog je ostao sačuvan audio-zapis.

3 Treba napomenuti da u je navedenim istraživanjima bilo više od 25 iskaza koji su posvećeni merenjima vrednosnih orijentacija.

4 Ukoliko je odgovor „pozitivan“ (odgovori pod 1 i 2), potpitanja su bila: a) Šta za Vas znači da se neko oseća sasvim sigurno?; b) Zašto se čovek ne može osećati sigurnim ukoliko živi u sredini gde većina stanovnika nisu pripadnici njegove nacije?; c) Da li se pod nekim uslovima može osećati sigurno iako čini nacionalnu manjinu u mestu u kojem je nastanjen?

Ukoliko je odgovor „negativan“ (odgovori pod 4 i 5), potpitanja su bila:

a) Šta za Vas znači da se neko oseća sasvim sigurno?; b) Da li se pod nekim uslovima ne može osećati sigurno ako čini manjinu u mestu u kojem je nastanjen? [Ukoliko je odgovor potvrdan:] Pod kojim uslovima? 
Najznačajniji nalaz u vezi sa iskazom, kao indikatorom čiju validnost $\mathrm{u}$ ovom slučaju istražujemo, jeste pitanje konteksta. Preciznije, možemo u znatnom broju slučajeva videti da je referisanje na određeni geografski, odnosno politički i bezbednosni kontekst u uskoj vezi sa razjašnjenjem samog odgovora na postavljeno pitanje. Tako se neslaganje sa tvrdnjom 'opravdava' pozivanjem na 'uređene' ili 'normalne' zemlje Zapada. Sa druge strane, slaganje sa tvrdnjom opravdava se međuetničkim sukobima u regionu (Balkan).

Ispitanik: „Pa, recimo, primer da je neko naš otišao negde u inostranstvo pa je postao gastarbajter, pa živi tamo, pa dobije na kraju decu i unučiće. Svi žive u nekom drugom okruženju i svi imaju priču o finansijskoj $i$ bezbednosnoj sigurnosti u tim drugim zemljama gde su otišli u svom okruženju. Tako da ne mora da živi sa pripadnicima svoje nacije da bi se osećao sigurno.“ (odgovor: „ne slažem se“, sanitarno-ekološki tehničar, 35 godina)

Ispitanica: „Ja sam odrasla u Nemačkoj, fantastično sam se osećala. Nisam osetila nikada da sam stranac. Prihvatili su me u školi $i$ svuda. I ja nikada nisam imala nikakvih problema. Stvarno. Eto, to je druga nacija, nema veze sa nama. Čak su oni mene prihvatili kroz druženje, kroz sve.“ (odgovor: „,ne slažem se“, penzionerka, 67 godina)

Ispitanica: „Pa da, jedino, eto tako, mislim u zemlji gde su većinski pripadnici njegove nacije da se čovek jedino tu može osećati sasvim sigurnim, a ja ne smatram da se čovek jedino tu može da se oseća. Mislim da u stabilnim državama, zemljama gde je sve uređeno, čovek bez obzira na naciju može osećati sigurnim...“ (odgovor: „niti se slažem, niti se ne slažem“, penzionerka, 63 godine)

Ispitanica: „Pa, odmah sam pomislila na veliki broj, na primer, naših ljudi koji ide u inostranstvo da bi jednostavno bili u boljoj finansijskoj situaciji, da bi došli do boljeg života. I smatram da, ovaj, nisu ugroženi zato što žive $u$, na primer, u Americi ili ne znam gde."

B. F: „Pošto si zaokružila pod tri, dakle onda bi to bio ovaj deo sa kojim se ne slažě̌?

Ispitanica: „Zavisi u kojoj državi su..."

B. F: „Kako bi to podelila? Gde važi, a gde ne važi?"

Ispitanica: „U islamskim državama ipak postoji razlika da li je neko musliman ili nije..." (odgovor: „niti se slažem, niti se ne slažem“, studentkinja, 24 godine)

Ispitanik: ,... shvatio sam da ako se pita da čovek može biti samo siguran ako živi sa svojim narodom. Mislim da ne, zato što... u zavisnosti kakav je čovek može bilo gde da bude siguran. I, između ostalog, u kakvoj zemlji živi. Nijedan čovek neće biti siguran ako živi u zemlji koja je u rasulu rata... nebitno... nesuglasice, kriminal. Ali generalno mislim da čovek može svugde da se snađe $i$ da bude siguran.“ (odgovor: „ne slažem

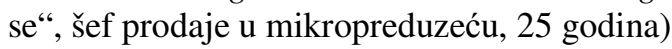


Ispitanik: „Pa znaš šta, a to u kojoj zemlji mi živimo i u koje vreme, to da. Ali to u normalnom svetu mislim da to ne bi trebalo da bude. Sada ne znam šta da ti odgovorim?

B. F: Ajde neka bude Srbija? Da li bi u Srbiji mislite da to važi?“ na) Ispitanik: „Za Srbiju da“ (odgovor: „slažem se“, portir, 50 godi-

Kontekstualizacija se ne mora odnositi samo na zemlje Zapada. U slučaju dvojice ispitanika Beograd predstavlja primer kojim se 'pobija' važenje navedene tvrdnje.

Ispitanik: „Pa razumeo sam ga bukvalno. Evo, ovde na primer, konkretno u Beogradu živi... postoji gomila nacionalnih manjina i ne vidim da im fali bilo šta.“ (odgovor: „,ne slažem se“, računarski tehničar, 34 godine)

U još jednom slučaju se javlja šire područje grada Beograda kao kontekst kojim se osporava važenje date tvrdnje. Ipak, važno je napomenuti da je ispitanik pripadnik slovačke nacionalne manjine, te je odgovor društveno poželjan, posebno s obzirom na činjenicu da je razgovor vodio autor ovog teksta, dakle pripadnik većinskog naroda:

Ispitanik: „Pa ništa, eto, ja živim u okruženju gde ima i Bosanaca i Hrvata i Srba i Slovaka, znači i svi se slažemo i sve je OK." (odgovor: „ne slažem se“, radnik, 35 godina)

Zanimljivo je da se u jednom slučaju ponovo javlja kontekstualizovanje odgovora, ali se nacija kojoj pripada ispitanik javlja s vrednosno negativnim predznakom.

Ispitanik: „Pa otprilike kada živiš u zemlji gde je tvoja nacija ili u inostranstvu gde se nalaze uglavnom pripadnici tvoje nacije. Mislim, po meni je to bezveze. Ne, apsolutno ne. Mislim da bih se ja čak nesigurnije osećao ovde nego negde gde uopšte nema moje nacije. Možda zato što svoju naciju ne doživljavam kao neku ekstremno poštenu, dobru i ne znam ni ja kakvu.“ (odgovor: „, potpunosti se ne slažem“, grafički dizajner, 37 godina)

Možemo uočiti i odgovore koji svoje neslaganje sa tvrdnjom objašnjavaju svođenjem problema na individualnu ravan. U naredna dva odgovora uočavamo veoma slična obrazloženja odgovora iako su oni (na Likertovoj skali stavova) bili različiti.

Ispitanica: ,Mislim da to zavisi od osobe, mislim da stvarno zavisi od osobe do osobe. Mislim da osoba koja je spremna da živi bilo gde $i$ može to da prihvati da će biti podjednako srećna u potpuno nekom drugom okruženju. I da prosto osoba koja nije spremna na to neće biti, ne znam, ni u komšiluku. Misli da to stvarno zavisi od osobe do osobe i ne može da se generalizuje uopšte.“ (odgovor: „niti se slažem, niti se ne slažem“, poslovna sekretarica, 46 godina) 
Ispitanik: „pa razumeo sam da neki pojedinac može da živi samo u okolini gde su i pripadnici njegovog naroda, što mislim da je potpuno netačno. Sve je od osobe do osobe, i svaka individua je za sebe. Nekome je to bitno i možda se stvarno oseća najbolje među pripadnicima svog naroda, a nekome nije. Zato se ne slažem. Nije sve isto.“ (odgovor: „,ne slažem se“, arhitekta, 33 godine)

Ispitanica: „Sasvim sam ga jasno [shvatila]... ovako kako jeste. Ne slažem se uopšte, zato što vam pripadnost vašoj naciji uopšte ne garantuje apsolutnu sigurnost... sigurnost ovog tipa, znači, ovo da se čovek može osećati sasvim sigurno samo kada živi... nije tačna.“ (odgovor: „, ne slažem se“, nezaposlena, 55 godina)

Na primeru narednog odgovora vidimo da je šire shvatanje pojma, sigurnosti koje izlazi van okvira međunacionalnih (ili međuetničkih odnosa ${ }^{1}$ ) razlog za neslaganje sa samim iskazom, dok u drugom iskazu pronalazimo samo lakonsko neslaganje sa iskazom, tj. njegovo odbacivanje.

Ispitanica: „Odmah sam pomislila da se čovek bez obzira na naciju, na bilo šta u principu, ne može osećati i nije garancija da će se osećati sasvim sigurno, to jest, ne može se osećati sigurno ni u jednoj sredini. Uvek ima svakakvih pretnji, a ne samo da su oko tebe pripadnici iste nacije. Mislim da je to mnogo širok pojam da se neko oseća sigurnim." (odgovor: „ne slažem se“, nezaposlena, 52 godine)

Ispitanica: „Pa, mislim, šta to ima veze. Me ne, uopšte nema veze kad pogledaš... E sad zavisi kakvu sigurnost?" (odgovor: „,ne slažem se“, nezaposlena, 56 godina)

U slučaju jedne ispitanice vidimo 'pomeranje' ili 'ublažavanje' odgovora zbog jednog dela iskaza.

Ispitanica: „Nije jedan samo zato što piše 'samo kada', mislim, realno, mene ovde neko može da ubije..." (odgovor: „slažem se“, nezaposlena, 20 godina)

Sa druge strane, zanimljivo je da ispitanici koji saglasni sa tvrdnjom (ili su zauzeli ambivalentni stav) navode upravo primere iz regiona koji se posmatraju kao poprište međunacionalnih netrpeljivosti:

Ispitanik: „Znaš, kako. Odeš na more. Ja sam imao priliku da odem 2009. godine na more, na Pag, sa pet svojih drugara. Brate, nije ti svejedno. Na more odeš. Eto, lupam. Neki regionalni problemi... Srbi, Hrvati, Bosanci... Odem na more, nije mi svejedno. Odeš u prodavnicu da kupiš hleb, ona te gleda. Na more odeš, a ne da živiš..." (odgovor: „niti se slažem, niti se ne slažem“, tehničar, 32 godine)

Ispitanik: „Pa sigurnim ono... e tu sad dolazi do sukoba, jedno kažem... a drugo ću sad. Ovo je sigurnije, kada tvoja nacionalnost, opet si nekako... šta ja znam, k’o na Kosovu što se dešava... Šiptari što pale.

1 U radu ne insistiramo na razlici između nacije i etničke zajednice, bez obzira na teorijsku opravdanost ovakvog razlikovanja. 
Kako nas obaveštavaju, na osnovu toga.“ (odgovor: „slažem se“, domar, 50 godina)

Ispitanica: „Pa normalno. Zato što je siguran. Narod je njegov oko njega i nema šta da se plaši. A kada je mešavina onda se svaki čas... okreće se ko će da te tresne po glavi.“ (odgovor: „slažem se“, penzioner$\mathrm{ka}, 75$ godina)

U jednom slučaju učesnica svojim odgovorom otvara pitanje da li se iskaz shvata kao opis 'realnog' stanja stvari ili kao normativni iskaz. Moramo napomenuti da je ova dilema (jeste versus trebalo bi da bude) prisutno kao problem i u drugim indikatorima (pitanjima) našeg istraživanja.

Ispitanica: „Pa razumela sam... Mislim da je to inače tako u našoj psihi. Kada smo okruženi našim ljudima iste nacije... i zbog toga. Ali mislim da ne bi trebalo tako. Ali mislim da je zbog toga." (odgovor: „slažem se“, studentkinja, 22 godine).

Na kraju, javljaju se i odgovori u kojima ne možemo jasno razlučiti zašto se ispitanik opredelio baš za dâti odgovor na Likertovoj skali.

Ispitanik: „Ne znam, kako je u principu... da ja živim... mislim mogu da zamislim kako bi se ja ponašao i ophodio. Nisam baš puno vremena proveo u nekoj sredini gde... Znaš, mislim... ti, recimo, možeš da imaš bolje dobrosusedske odnose sa komšijom a on isto može biti Hrvat ili Albanac. A može biti ubica i lopov. Nema tu pravila. Čovek se oseća sigurno dok čuva svoj jezik... znaš. Iako svi mi govorimo istim jezikom. Mislim, na ex-Yu prostorima. Eto, on je, kao, deo tvog porekla, deo tvoje neke zemlje ili deo iste vere. I više se ljudi zbližavaju na takav način nego da... Ali ja sam u principu $i$ za jedno i drugo. Da odeš kod komšije na Božić ili da odeš kod drugog komšije na, tipa, Bajram ili na Ramazan. Da imaš isti podjednako isti pristup ili isto shvatanje njihovih života." (odgovor: „slažem se“, niži rukovodilac u supermarketu, 31 godina)

Smatramo da bi potpitanje (,کŠta za Vas znači da se neko oseća 'sasvim sigurno" ") moglo biti od posebne važnosti za istraživanja u području bezbednosti. Iako ne mora uvek biti od neposrednog značaja za metodološki problem pouzdanosti (validnosti), smatramo da nam odgovori daju interesantne uvide u problematiku kvantitativnih istraživanja vrednosnih orijentacija, međuetničkih odnosa i bezbednosti. Najveći broj ispitanika je na naše potpitanje podrazumevao fizičku sigurnost.

B. F: „A šta za tebe znači da se neko 'oseća sasvim sigurno’?"

Ispitanik: „Pa sad, recimo, kada izlaziš na ulicu, pa da li će neko da te mlatne, da li će da te odžepari, da li će da te pokrade. Otkud znam. Eto tako, ne vidim nikakve druge..." (grafički dizajner, 37 godina)

B. F: „Šta za Vas znači da se neko oseća 'sasvim sigurno'? Kako ste shvatili taj deo 'osećati se sasvim sigurno'?"

Ispitanica: „Sasvim sigurno se oseća čovek koji ne misli da ako izađe maltene ispred svojih vrata, može da bude na bilo koji način ugnje- 
tavan ili napadnut. Bilo to verbalno ili fizički u najtežem slučaju. Recimo, da mu se atakuje na život, na opstanak itd." (nezaposlena, 55 godina)

B. F: „Kako ste razumeli 'sasvim sigurnim', da se neko oseća 'sasvim sigurnim'?"“

Ispitanica: „Pa sasvim siguran, po meni čovek baš ne mora da se oseća sasvim siguran, potpuno siguran.“

B. F: „Šta ste pomislili kada ste čuli odnosno pročitali ovaj deo 'osećati sasvim siguran'? Šta za Vas znači 'sasvim sigurno'?"

Ispitanica: „Ja sam prvo pomislila, ovaj, bezbedan. Bezbedan u smislu fizičke bezbednosti.“ (penzionerka, 63 godine)

B. F: „A šta za Vas znači da se neko 'oseća sasvim sigurno'?“”

Ispitanik: „Sigurno ono... da te ne tuče neko, znaš, da ti ne upada u kuću, da ti ne razbija nešto... na silu, znaš.“ (domar, 50 godina)

B. F: „Šta za tebe znači da se neko oseća sasvim sigurno? U ovoj rečenici kako si shvatila?"

Ispitanica: „Pa to da mogu da znam, da, tipa, uveče kada se vraćam kući svojoj, ne moram da strepim, da l' će šta će da mi iskoči."

B. F: „U smislu da te napadne?“

Ispitanica: „Da, da. A i ovako da mi na primer, da neće, ne znam sad... zamisli živiš negde i ono odjednom se svi nešto pobune i nešto krenu u neko ludilo i ti, kao, nemaš pojma šta se dešava. Nekako znaš da toga ovde baš neće biti. A i da se desi, opet znaš nekako su tvoji, znaš šta može da izađe iz toga." (nezaposlena, 20 godina)

B. F: „Šta za Vas znači da se neko 'oseća sasvim sigurnim'?“

Ispitanik: „Šta ja znam. Da nema problema od komšije. Šta ja znam, kao što je dole na Kosovu. To sam mislio. A inače, čovek ne može da se oseća sigurnim od lopova. Evo kod mene su dole za dan opljačkali pet kuća i nikom ništa. Evo posle par dana dve su kuće opljačkali. Tako da sa te strane ne možeš da budeš siguran nigde." (portir, 50 godina)

B. F: „Šta za tebe znači da se neko 'oseća sasvim sigurno'?“

Ispitanik: „Nemam potrebe [sic]. Nisam nikada, ono, bio nešto ugrožen, ono da me kinji, da me ne znam šta. Da misli nešto protiv mene. Znači, osećam se sasvim slobodno u tom okruženju."

B. F: „Da te neko ne kinji, to se podrazumeva..."

Ispitanik: „Da, da nema ništa protiv mene.“ (radnik, 35 godina)

B. F: „Šta znači da se neko 'oseća sasvim sigurno'?"

Ispitanica: „Da neće da ga napadne. Zna da su svi dobri, da su svi njegovi oko sebe i onda neće. Ako ima tu muslimana, Šiptara, šta ja znam, može da se nada svaki čas." (penzionerka, 75 godina) 
Osim značenja koja se više ili manje eksplicitno odnose na fizičku ugroženost, javljaju se i odgovori koji nam ukazuju da sintagma 'osećati se sasvim sigurno' za ispitanike/-ce ima šire značenje. Pored već navedenog razumevanja, uočavamo i interpretacije koje u ovu sintagmu 'uključuju' i druge elemente - ekonomske, kulturne i političke.

B. F: „Šta za tebe znači da se neko oseća 'sasvim sigurno'? Šta za tebe znači taj deo tvrdnje?"

Ispitanik: „Da se oseća komforno na prostoru gde živi. Da se oseća sigurno bezbedonosno i ekonomski, kulturno. Da može sve svoje potrebe... da... kako da kažem... da zadovolji.“ (arhitekta, 33 godine)

B. F: „Šta za tebe znači da se neko 'oseća sasvim sigurno'?“"

Ispitanik: „Pa finansijski, bezbednosno, politički.“ (sanitarno-ekološki tehničar, 35 godina)

B. F: „Šta za tebe znači 'osećati se sasvim sigurno'?“

Ispitanica: „Potpuna sigurnost ne postoji po meni... pošto se nije nigde kategorizovalo na šta se tačno misli. Imaš svakakvu nesigurnost. I ne znam. Ako se krene od sopstvenog nekog eventualnog slučaja do ugrožavanja života, pa do materijalne sigurnosti, do socijalne sigurnosti, do tvoje pozicije sigurnosti... ne znam, zadržavanja posla. Znači, sve je vezano... svi aspekti u današnjem životu stvarno su vezani toliko da može očas posla da ti bude očas posla sigurnost ugrožena na ovaj ili onaj način. Ali ne mislim život, nego tvoje poimanje sigurnosti.“

B. F: „Za tebe sigurnost ne znači samo fizička sigurnost?““

Ispitanica: „Ne, ne.“ (nezaposlena, 52 godine)

B. F: Da li za tebe 'osećati se sasvim sigurno' znači životnu sigurnost i nesigurnost?

Ispitanica: „Da, ja sam u tom smislu shvatila. Životnu ugroženost... a druga vrsta ugroženosti - mislila sam na finansije. Da li neko ima pravo da radi, da dođe do istog posla kao i neko drugi." (studentkinja, 24 godine)

B. F: „Šta za tebe znači da se neko oseća sasvim sigurno? Pošto ovde stoji 'osećati se sasvim sigurno'?"

Ispitanik: „Pa sasvim sigurno u smislu živeti normalnim životom. Bez neke bojazni da će neko na ulici da te opljačka, ubije, žene, ne znam, siluje. Da imaš normalan neki posao, normalno da živiš, normalno da zarađuješ. Sad, opet, to je diskutabilno šta je normalno, ali pričam za neki normalan život - da ni u čemu nešto ne oskudevaš a da živiš normalno." (šef prodaje u mikropreduzeću, 25 godina) 
Uočavamo i interpretacije koje ukazuju na kvalitet međuljudskih odnosa u svakodnevnom životu, a kao 'kriterijum' sigurnosti se izdvaja poverenje među ljudima.

B. F: „U okviru ove rečenice šta za tebe znači da se neko oseća 'sasvim sigurno'?"

Ispitanik: „Mislim, da živi u harmoniji, nije to sad neko blagostanje. Nego, prosto, siguran si u okruženje. Znači, polaziš, recimo, od komšije. Da možeš njemu da ostaviš ključ, recimo, ako odeš na more. Da ti on obilazi kuću. Tipa da keva tamo zaliva biljke. Da živiš u zgradi sa [ljudima - B. F.] sa kojima se možeš dogovoriti oko nekih stvari. Da živiš u gradu koji je... da imaš što više poznanstava, da znaš što više ljudi... tako širiš taj krug, tako se širi sigurnost." (niži rukovodilac u supermarketu, 31 godina)

Uopštenija shvatanja pojma 'sigurnosti' pronalazimo kod jedne ispitanice i jednog ispitanika. U prvom slučaju možemo uočiti da se zemlja Zapada (Nemačka) javlja kao primer bezbednosti u kontekstu međunacionalnih odnosa. shvatili?"

B. F: „Šta znači da se neko oseća 'sasvim sigurno'? Kako ste to

Ispitanica: „Znate šta, normalno, da vas niko ne ponižava što ste u toj drugoj naciji. Da živite složno, da funkcioniše sve kako treba, normalno, brate. Ja sam to doživela u Nemačkoj $i$ - mogu da vam kažem fantastično." (penzionerka, 67 godina)

B. F: „A šta za tebe znači da se neko 'oseća sasvim sigurno'?““

Ispitanik: „Znači da ne može bilo šta da mu se desi. Da neće biti... neće se osećati potišteno na nacionalnoj osnovi ili [na osnovu] bilo čega drugog." (računarski tehničar, 34 godine)

U slučaju jedne ispitanice pojam sigurnosti se ne dovodi u vezu sa bilo kojim područjem, već poprima značenje ostvarenja slobode.

B. F: „To je ono što hoću da te pitam šta za tebe znači da se neko 'oseća sasvim sigurno'? Na šta si ti pomislila?"

Ispitanica: „Pa slobodni. Na slobodu.“

B. F: „Kada kažeš 'sloboda'...“

Ispitanica: „Sloboda kretanja, sloboda izražavanja, sloboda razmišljanja." (nezaposlena, 56 godina)

Na kraju, zanimljivo je da se u slučaju dva odgovora eksplicitno negira bilo kakva povezanost sa fizičkom ugroženošću. Dok se u jednom primeru (studentkinja, 22 godine) javlja ograničavanje na sferu rada, u drugom se susrećemo sa jasnom negacijom ograničenja 'osećanja potpune sigurnosti' na fizičku ugroženost. 
B. F: „ک̌ta za tebe znači da se neko 'oseća sasvim sigurno'? Dakle, u delu ovog iskaza... kako si shvatila ovo 'sasvim sigurno'?"

Ispitanica: „Da će tu gde je većina, da će možda naći posao pre nego neko drugi. Sasvim sigurno... ili, recimo, izgubiti posao u firmi u kojoj radi. Mislim da bi se tu osećao sigurnije nego tamo gde je nacionalna manjina."

B. F: „Da li ima još nešto možda? Ako ti ne pada na pamet, sasvim je dovoljno? Prosto pitam."

Ispitanica: „Ne.“ (studentkinja, 22 godine)

B. F: „A šta za tebe znači da se neko oseća sasvim sigurno. Na šta si pomislila kada si pročitala?"“

Ispitanica: „Pa, vidi, ja sam pomislila prvo na tu neku toplinu, na tu neku bliskost.“

B. F: „Među ljudima?“

Ispitanica: „Da, da, na te neke međuljudske odnose koji su bliski. Ja sam pomislila na to. Znači, ne mislim sad na neku nesigurnost fizičku ili, ono, strah koji postoji. Nego mislim prosto na te međuljudske odnose svakodnevne koji manje-više funkcionišu sasvim normalno." (poslovna sekretarica, 46 godina)

Na samom kraju želeli bismo da ukažemo na nekoliko primera koji nam govore koliko ili kako se (re)interpretira iskaz („Čovek se može osećati sasvim sigurnim samo kada živi u sredini gde je većina pripadnika njegove nacije") kada se postavi i potpitanje o granicama važenja odgovora koji su ispitanici/-ce prvobitno dali.

B. F: „Da li se ne može osećati sigurno ako čini manjinu u mestu u kojem je nastanjen?"

Ispitanik: „Da li se neko može osećati nesigurno?“”

B. F: „Da, da li se pod nekim uslovima ... dakle, ti si rekao da ovo ne važi, ti se ne slažeš sa tvrdnjom."

Ispitanik: „Da, da, može se osećati nesigurno.“

B. F: „Pod kojim uslovima?“"

Ispitanik: „Pod uslovima da ili on ima problem sa tom zajednicom ili ta zajednica ima problem sa njim. Sada, ne kažem ni da zajednica može da bude kriva... mislim, može $i$ on $i$ većina da bude kriva." (odgovor: „,ne slažem se“, arhitekta, 33 godine)

B. F: „Da li se pod nekim uslovima može osećati sigurno iako čini nacionalnu manjinu u mestu u kojem je nastanjen... Kada kažem 'neko', mislim na nekog pojedinca?"

Ispitanik: „Pa dobro, to zavisi od dela zemlje, od grada...“

B. F: „Aha, reci mi kako zavisi, kako ti to vidiš?"“ 
Ispitanik: „Pa dobro, sad trenutno na Kosovu ne, u Bosni je, opet, bilo primirje, ali opet je počelo sa ovim ratnohuškačkim govorima, mislim, može biti siguran samo ako je okružen UNHCR-om, KFOR-ovcima, tenkovima."

B. F: „A reci mi da li ima neki pozitivan. Ako su Bosna i Kosovo negativan primer, da li ima neki pozitivan primer. Da može da se oseća sasvim sigurno iako pripada... iako čini manjinu u mestu u kojem je nastanjen."

Ispitanik: „Može, 'ajde, šta mi je sada palo na pamet. Mogu, recimo, ona sela gore po Sremu, po Banatu. Gde su došli ovi Krajišnici, Hrvati ušli, naravno, u kuće, imanja. Rade i žive. Mislim da to nije nikakva prepreka. Našoj državi, zemlji, našem sistemu.“ (odgovor: „slažem se“, niži rukovodilac u supermarketu, 31 godina)

B. F: „Da li se po nekim uslovima može osećati sigurno iako čini nacionalnu manjinu u mestu gde je nastanjen? Neki čovek, bilo koji.“

Ispitanik: „Može, sigurno... jedino, ja mislim, na Zapadu. U Nemačkoj, u Švedskoj, tamo u Skandinaviji. Koliko-toliko koje su drugačije malo od nas... I drugi sistem.“ (odgovor: „slažem se“, domar, 50 godina)

B. F: „Da li se, pod nekim uslovima, taj čovek o kojem sada govorimo ne može osećati sasvim sigurno ako čini manjinu u mestu u kojem je nastanjen. Da li postoje neke okolnosti, neki uslovi, da se neko ko čini manjinu u mestu u kojem živi ne oseća sigurno?"

Ispitanik: „Sigurno da može u slučaju nekih...“

B. F: „Koji su to slučajevi, u kojim okolnostima. Ako ti nešto pada na pamet.“

Ispitanik: „Pa isto u tim nekim ratnim... evo, recimo, u ratu.“ (odgovor: „ne slažem se“, računarski tehničar, 34 godine)

B. F: „Da li se po nekim uslovima ne može osećati sigurno ako čini manjinu u mestu u kojem je nastanjen?"

Ispitanik: „Pa to ne znam, nisam živeo...“"

B. F: „Nemaš lično iskustvo?"“

Ispitanik: „Da, da... verujem opet da postoje sredine gde može $i$ sredine gde ne može. Jednostavno, opet zbog tih nekih nacionalnih, političkih ili, šta ja znam, problema među nacijama.“ (odgovor: „u potpunosti se ne slažem“, grafički dizajner, 37 godina)

B. F: „Da li se pod nekim uslovima ne može osećati sigurno?“” Ispitanik: „Da, postoje isto primeri gde su ljudi u manjini...“ B. F: „Koji su to primeri?“

Ispitanik: Pa, ne znam. Pa, pretpostavljam, Srbi u određenim delovima Kosova. Neki Srbi u Prištini, u Peći, gde su baš manjina, i u takvoj državi sa takvom istorijom, sa prethodnim ratom se ne osećaju sigurno samo zato što su druge nacionalnosti, veroispovesti.“ 
B. F: „Misliš, dakle, da to zavisi od države ili od sredine u kojoj se živi?"

Ispitanik: „Pa od ukupnih okolnosti u mestu o kojem se govori. Mislim, Njujork i Priština su dve različite stvari. U Njujorku postoji mnogo nacija pa svi sarađuju kako treba. U Prištini postoji malo drugih nacija, pa se verovatno osećaju nesigurnije.“ (odgovor: „ne slažem se“, sanitarno-ekološki tehničar, 35 godina)

B. F: „Da li se pod nekim uslovima čovek ne može osećati sigurno ako čini manjinu u mestu u kojem je nastanjen?“

Ispitanica: „Pa ako je manjina ugrožena, ako je neko ratno područje... Kosovo, na primer.“ (odgovor: „,ne slažem se“, nezaposlena, 56 godina)

B. F: „Da li se pod nekim uslovima čovek ne može osećati sigurno ako čini manjinu u mestu u kojem je nastanjen?"

Ispitanica: „Pa, zavisi gde je.“

B. F: „To Vas pitam, da li mislite da tu postoje neke razlike?“

Ispitanica: „Pa postoji razlika, ako si u normalnoj i demokratskoj sredini i državi, ta manjina neće se osećati ugroženom, ali..."

B. F: „A gde će se osećati?“"

Ispitanica: „Ali zamisli ti sada na Kosovu, sa tom manjinom. To je opasno, e to je strašna stvar. Ili zamisli da si ti sad, na primer... Možda je malo ružno, ali činjenica, istina je takva. Sad ne mora da bude samo za nas. Može da bude i za druge nacije. Znate. Ja imam puno prijatelja u Banjaluci i ima jedna porodica muslimanska i jedna hrvatska... dve-tri hrvatske. Ne osećaju se baš prijatno. Znate, i mi umemo da budemo malo... a i oni isto. Sad, sve to zavisi gde si i šta si. Ako si u normalnoj državi, kao što si u Nemačkoj, kao što si u Austriji, kao što si u Švajcarskoj, ti to nećeš ni da osetiš. Je l' tako? Gde je civilizovan svet. Dođi ti kod Šiptara dole. Traži ti to. To nema šanse. Je l' tako? A i nisu ovi naši u Bosni bolji.“ (odgovor: „,ne slažem se“, penzionerka, 67 godina)

B. F: „Da li se pod nekim uslovima ne može osećati sasvim sigurno ako čini manjinu u mestu u kojem je nastanjen?“ zemljama."

Ispitanik: „Opet kažem, može jedino u nekim našim balkanskim

B. F: „A koji su to uslovi ili koje su to zemlje?“

Ispitanik: „Pa ne znam, lupam, ako manjina Srba živi u Hrvatskoj, mislim da se ne može osećati sigurno. Ili u ovom slučaju manjina Srba na Kosovu... Kao što sigurno ni manjina Slovenaca u Hrvatskoj, jer je jednostavno velika netrpeljivost. Mislim da se ne može osećati sigurno, sasvim sigurno. Možda se može osećati sigurno... delimično, ali sasvim sigurno - ne.“ (odgovor: „ne slažem se“, šef prodaje u mikropreduzeću, 25 godina) 


\section{Zaključak}

Na samom kraju želimo istaći da se pitanje konteksta javlja kao ključni problem u pokušaju da se validnost jednog indikatora kritički promisli. Drugim rečima, pristup koji smo primenili pokazuje ograničenja u ne tako malom broju slučajeva. Teškoća se ogleda u saznajno problematičnom odnosu između vrednosti ispitani$\mathrm{ka} /$-ca (nacionalizam) i primera (prostornog konteksta) na koji se njihov odgovori odnose.

Da li vrednosti određuju kontekst (geografski i politički) koji se navodi kao primer za sopstvene odgovore? Da li se javlja u odgovorima kontingentnost, koja se kasnije 'pravda' različitim primerima? U prvom slučaju bi validnost indikatora bila potvrđena u većini slučajeva.

Neosporno je da se 'uređene', 'normalne', 'civilizovane' zemlje Zapada pojavljuju kao primer za one ispitanike/-ce koji se ne slažu sa tvrdnjom (ili suprotno, Balkan i Orijent kao primeri netrpeljivosti za one koji su saglasni sa iskazom). Međutim, videli smo da kroz potpitanje o mogućim izuzecima koji mogu nastupiti u pogledu univerzalnog važenja iskaza iskrsava konvergencija diskursa o odnosu sigurnosti i etničke pripadnosti. Tačnije, kontekstualizacija postaje još izraženija, ali i razlike u odgovorima ispitanika postaju manje.

Sa druge strane, očigledno je da su razumevanja koja učesnici/-ce pridaju sintagmi 'sasvim sigurno' mnogoznačna. Iako većina ispitanica/-ka pojam blisko vezuje za pitanje fizičke sigurnosti, u velikom broju slučajeva ona nije jednoznačan pojam. Dakle, osim fizičke bezbednosti, uključuje i pitanja ekonomije, kulture i političkih sloboda. Takođe, videli smo da su se u dva slučaja javili odgovori koji, direktno ili indirektno, sasvim isključuju značenje fizičke sigurnosti.

\section{Literatura}

1. Brinberg, David (1985): Validity and the research process, SAGE Publications, London.

2. Goertz, C. \& Mahoney, J.: A Tale of Two Cultures: Qualitative and Quantitative Research in the Social Sciences, Princeton university press, Princeton, 2012.

3. Jick, T.: „Mixing Qualitative and Quantitative Methods: Triangulation in Action“, Administrative Science Quarterly, Vol. 24, No. 4, pp. 602-611.

4. Lazić, M.: Čekajući kapitalizam: nastanak novih klasnih odnosa u Srbiji, Službeni glasnik, Beograd, 2011.

5. Lazić, M. (prir.): Politička elita u Srbiji u periodu konsolidacije kapitalističkog poretka, Čigoja, ISI, Beograd, 2016.

6. Petrović, I.: „Promene vrednosnih orijentacija srednje klase u periodu post-socijalističke transformacije u Srbiji“, Sociologija, Vol. LV (2013), № 3, str. 375-394.

7. Pešić, J.: Vrednosne orijentacije u post-socijalističkim društvima Srbije i Hrvatske [doktorska disertacija], Beograd, 2016.

8. Fajgelj, S.: Metode istraživanja ponašanja, Centar za primenjenu psihologiju, Beograd, 2010.

9. Hesse-Biber, Sharlene and Johnson, R. Burke (2015): The Oxford Handbook of Multimethod and Mixed Methods Research Inquiry, Oxford University Press, Oxford. 


\section{SAFETY AND ETHNIC RELATIONS - PERCEPTION OF THE PROBLEM IN THE CONTEXT OF SETTLEMENT AND COEXISTENCE}

\section{Summary}

This paper presents the results of qualitative studies conducted on the territory of the city of Belgrade. Focusing on the methodological principle of validity, we have analysed the results of the quantitative sociological studies of the social structure, which have been conducted in Serbia and the former Yugoslavia ever since the eighties, under the direction of Prof. Mladen Lazić. One of the statements used in this research refers precisely to the question of security, as follows: "One can feel completely safe only when living in an environment with the majority of members of their nation." Regarding the fact that in these quantitative research answers were always pre-defined, or limited by the framework of the Likert scale, we wanted to critically rethink the answers to the (same) question. Therefore, in one part of our (qualitative) research, we have designed a series of sub-questions which has further clarified the respondents' answers and showed how and in what way they understand the key elements of the abovementioned statement. Thus, we present the interpretation of the problems and challenges of security in the context of inter-ethnic relations. More specifically, we will try to understand why the respondents are being determined by positive or negative value according to the statement, and how they explain their own choices.

Keywords: safety, quantitative and qualitative methodology, ethnic relations, interpretation 